Especialmente para o caso do Turismo, há de se reconhecer a importância dos seus principais agentes econômicos envolvidos, ou seja: os turistas, as empresas, o governo e a comunidade anfitriã. Nesse capítulo, os autores abordam os objetivos de cada um desses grupos, além de ilustrarem o texto com explicações gráficas de curvas de indiferença e de restrições orçamentárias, bem como do comportamento dos custos marginais, adotando, como exemplo, o caso específico de uma hipotética empresa hoteleira.

São ainda apresentadas algumas considerações sobre o efeito multiplicador da renda, e de outros macroefeitos gerados pelo Turismo.

Por fim, são feitas algumas colocações econômicas sobre a demanda para o Turismo, dentre elas, comentam algumas de suas principais características, como a elasticidade-preço e a elasticidade-renda.

A quarta e última parte do livro - Práticas e Filosofias do Turismo - contém três capítulos: Como se Organiza o Turismo (10); Investigação em Turismo (11); e, Filosofia para o Futuro do Turismo(12).

Fica bastante claro, com essa abordagem, que a organização do Turismo é muito complexa. O estudo abrange aspectos relacionados à atuação dos principais grupos oficiais de Turismo, em uma análise de suas principais funções, técnicas, e atividades de cooperação mútua. É citado, a título de ilustração, o organograma do órgão público de $\mathrm{Tu}$ rismo canadense, como exemplo de uma organização nacional-mode10.

Também nesta parte é enfatizada a necessidade de investigações e de estudos estatísticos, já que os programas de promoção são patrocinados pelas organizações de Turismo. Essas informações são de extrema importância para uma mais completa e real avaliação do mercado turístico, possibilitando indicações eficientes de melhores oportunidades de promoção pelas organizações, sejam elas privadas, estatais, regionais ou federais.

Concluindo, são escritas algumas das tendências mais significativas que afetam o futuro do turismo, como as tecnológicas, ambientais, e, inclusive, considerações específicas sobre a evolução do tempo livre que, numa civilização industrial moderna, é vital para um maior consumo de produtos turísticos.

Apresenta, ainda, um Glossário de algumas das principais expressões utilizadas pela atividade, como, por exemplo: Agências de Viagem; Destino; Excursionista; Pacotes; Passaportes; Serviços Terrestres; Tarifas; Turismo; Turista; Vôos Charter e outros. Além disso, complementando, estão relacionadas algumas das principais abreviaturas internacionais, tais como: ASTA (Sociedade Americana de Agentes de Viagens); $\mathrm{ABC}$ (Charter reservado com antecipação); DC
(Diner’s Club); FAA (Administração Federal da Aviação); IT (Inclusive Tour); WATA (Associação Mundial de Agentes de Viagens); XO (Ordem de Câmbio); e muitas outras siglas ou termos de uso freqüente na atividade turística.

Finalizando, recomenda-se a leitura atenta dessa obra, de fácil entendimento e evidente aplicação nas mais distintas áreas de conhecimento. Considera-se o livro de McIntosh e de Gupta um valioso instrumento, não só para os estudantes, mas para todos os interessados no campo do Turismo.

\section{“Managing Tourism"}

\section{Doris Van de Meene Ruschmann*}

MEDLIK, S. Managing Tourism. Oxford, Butterworth-Heinemann, 1991, 344 p.

O professor Medlik, organizador desta coletânea de textos, dirigiu durante dez anos o Department of Hotel, Catering and Tourism Management da University of Surrey (Guilford - Inglaterra) e, além de ter mais de uma centena de artigos publicados em revistas técnicas e de "papers" em congressos, escreveu vinte livros sobre Turismo.

Nessa obra, ele reúne as contribuições de trinta especialistas, cujos artigos foram publicados na revista "Tourism Management", durante a década de 1980 e que, devido à importância do seu conteúdo, não perderam a atualidade, servindo de referência para o leitor dos anos 90 , de qualquer parte do mundo.

Os textos selecionados refletem teorias, conceitos e práticas, pois Medlik entende que, no vasto campo do Turismo, a prática sem a fundamentação conceitual é estéril, e a teoria é o resultado de uma seleção de práticas.

Divide a obra em dez partes e cada uma delas apresenta a contribuição de vários autores que abordam diferentes temas de forma abrangente e clara, refletindo a situação da teoria e da prática do Turismo no final da década de 1980, projetando-a para a década de 1990. Os temas abordados são os seguintes: Evolução e Tendências do Turismo Mundial; Planejamento; Gestão e Desenvolvimento de Empresas Turísticas, Políticas Governamentais no Turismo; Con-

(*) Professora Assistente do Departamento de Relaçōes Públicas. Propaganda e Turismo da Escola de Comunicações e Artes da Universidade de Sảo Paulo. 
corrência entre Companhias Aéreas; Marketing de Produtos e Destinaçōes; Administração da Demanda Turística; Novas Tecnologias; Tendências para o Turismo no Terceiro Mundo; Limites e Riscos do Desenvolvimento Descontrolado do Turismo em Núcleos Receptores.

Além do cuidado com a seleção e o conteúdo dos textos, o organizador preocupou-se, também, com a distribuição eqüitativa da origem geográfica dos autores, e, assim, o livro representa o pensamento da comunidade científica de todas as partes do planeta, proporcionando ao leitor uma visão universal da atividade turística.

$\mathrm{Na}$ visão dos empresários modernos do Turismo, nos países desenvolvidos, a palavra do momento é "management" e, diante dessa realidade e pelo conteúdo dos textos, essa obra apresenta-se como extremamente atual, constituindo um rico material de consulta e de aprimoramento para profissionais, docentes, pesquisadores e estudantes de Turismo. 